\title{
Spontaneous alteration of blood pH by a bicarbonate buffer system during experimental hypercalcaemia in cows
}

\author{
Younghye $\mathrm{Ro}^{1}$, Woojae $\mathrm{Choi}^{1}$, Leegon Hong ${ }^{1}$, \\ Eunkyung Kim ${ }^{2}$, Eunhui Choe ${ }^{2}$, Danil Kim ${ }^{1,2,3 凶}$ \\ ${ }^{1}$ Department of Farm Animal Medicine, College of Veterinary Medicine, Seoul National University, Seoul, 08826, Korea \\ ${ }^{2}$ Farm Animal Clinical Training and Research Center, Institutes of Green-Bio Science and Technology, \\ Seoul National University, Pyeongchang, 25354, Korea \\ ${ }^{3}$ Research Institute for Veterinary Science, Seoul National University, Seoul, 08826, Korea \\ danilkim@snu.ac.kr
}

Received: March 17, $2021 \quad$ Accepted: September 23, 2021

\begin{abstract}
Introduction: Maintaining mineral homeostasis as well as the secretion and metabolism of mineralotropic hormones is important for healthy of periparturient dairy cows. To increase the activity of mineralotropic hormones, blood $\mathrm{pH}$ can be adjusted. The purpose of this study was to investigate changes in blood $\mathrm{pH}$ and the mechanism of action of this change in induced hypercalcaemic cows. Material and Methods: Six non-lactating Holstein cows were used in a $2 \times 2$ crossover design. To induce hypercalcaemia, calcium borogluconate was administered subcutaneously to experimental cows and normal saline was administered subcutaneously to control cows. Blood and urine samples were collected serially after administration. Whole blood without any anticoagulant was processed with a portable blood gas analyser. Plasma concentration and urinary excretion of calcium were measured. Results: In hypercalcaemic cows, both blood and urine calcium levels were significantly increased at $8 \mathrm{~h}$ compared to those at $0 \mathrm{~h}(\mathrm{P}<0.05)$, and a spontaneous increase in blood $\mathrm{pH}$ was also observed. The calcium concentration in plasma was highest at $2 \mathrm{~h}$ after administration $(3.02 \pm 0.27 \mathrm{mmol} / \mathrm{L})$. The change in $\mathrm{pH}$ correlated with that in bicarbonate $(r=0.781, \mathrm{P}<0.001)$ rather than that in partial pressure of $\mathrm{CO}_{2}(r=0.085, \mathrm{P}=0.424)$. Conclusion: Hypercalcaemia induced a spontaneous change in blood $\mathrm{pH}$ through the bicarbonate buffer system and this system may be a maintainer of calcium homeostasis.
\end{abstract}

Keywords: calcium, blood $\mathrm{pH}$, cattle, hypercalcaemia, bicarbonate buffer system.

\section{Introduction}

In dairy cows, disturbance of calcium (Ca) homeostasis causes productivity loss and production diseases $(2,7,14)$. In the body, endocrine factors are mainly responsible for maintaining the balance of $\mathrm{Ca}$, and their target organs include the intestines, the bones and kidneys $(2,8)$. However, to facilitate homeostatic processes, the entire environment of the body may be adjusted, including blood $\mathrm{pH}$ and the respiratory system $(1,4,9,10)$.

Many endocrine factors are known to control mineral levels, and the most well-known is the parathyroid hormone (PTH), the main function of which is to maintain optimal $\mathrm{Ca}$ levels in blood and to regulate Ca uptake or excretion by the bones and kidneys $(1,7$, $8,13,14)$. Parathyroid hormone activity is optimal when blood $\mathrm{pH}$ is mildly acidic $(1,9,10)$. Its antagonist calcitonin is secreted from the thyroid gland in a hypercalcaemic state and inhibits reabsorption of $\mathrm{Ca}$ and inorganic phosphate (iP) in the kidneys, thereby increasing the amount of $\mathrm{Ca}$ and $\mathrm{iP}$ excretion via urine $(3,5)$. Calcitonin also suppresses the action of osteoclasts releasing $\mathrm{Ca}$ from the bones, thereby reducing the Ca concentration in blood $(3,5)$. In addition, according to a previous study, the activity of calcitonin is known to decrease as blood $\mathrm{pH}$ decreases (11).

Our previous study showed a spontaneous decrease in plasma $\mathrm{pH}$ in cows that had hypocalcaemia; such a drop in $\mathrm{pH}$ is considered to maximise the effect of PTH (3). Although the mechanism of $\mathrm{pH}$ change was not explained as the $\mathrm{pH}$ was measured using plasma, our study showed that there is a mechanism which regulates the body environment so as to maximise the 
effectiveness of endocrine factors. Therefore, the purpose of this study was to determine whether a spontaneous change in blood $\mathrm{pH}$ in dairy cows is induced by hypercalcaemia and what mechanism underlies such a change.

\section{Material and Methods}

Experimental design. The study was conducted on six non-pregnant, non-lactating Holstein Friesian cows with parities of $1.33 \pm 0.82$ (mean $\pm \mathrm{SD}$ ), body weight of $710 \pm 39 \mathrm{~kg}$ and body condition score of $3.33 \pm 0.12$. Hay and concentrated feed were provided twice a day, and the cows were kept in a space with free access to drinking water and mineral blocks (Daehan New Pharm Co., Hwaseong, South Korea). The experimental animals were all kept under the same conditions, and no animals were moved nor other treatments administered throughout the experimental period. Three cows were subcutaneously injected with calcium; magnesium; dextrose (C.M.D., pH 3.56; Samyang Anipharm Co., Seoul, South Korea) containing $300 \mathrm{mg}$ of calcium borogluconate, $30 \mathrm{mg}$ of magnesium chloride, and $50 \mathrm{mg}$ of dextrose per $1 \mathrm{~mL}$ and these were the induced hypercalcaemic group (HYC). The remaining three cows were injected with $0.9 \%$ normal saline $(\mathrm{pH} 5.5$; Handong Co., Seoul, South Korea) and their purpose was to be the control group (CON). In both groups, $1 \mathrm{~L}$ of solution was subcutaneously administered per cow on both sides of the cervical region $(500 \mathrm{~mL}$ into each region) over $5 \mathrm{~min}$. Ten days later, this protocol was repeated, changing the groups. This study was approved by the Institutional Animal Care and Use Committee of Seoul National University (SNU-190522-3).

Sample collection. Blood and urine samples were collected at $0,1,2,4,8,12,18,24$, and $48 \mathrm{~h}$ after treatment. Blood samples were collected with a syringe connected to a $14 \mathrm{G} \times 5.25$ EQUIVET HiFlow Long-Term IV catheter (Kruuse, Langeskov, Denmark) previously installed. Blood for plasma chemistry analysis was aliquoted into a BD Vacutainer Lithium Heparin tube (Becton Dickinson, Franklin Lakes, NJ, USA), and the remaining whole blood in the syringe was used for blood gas analysis immediately after sampling. Urine samples were collected at every sampling time point through a BARDEX Urethral Catheter, (Medline, Northfield, IL, USA) which was introduced into the urethra and from there into the urinary bladder. Blood and urine samples were centrifuged at $2,000 \times g$ for $15 \mathrm{~min}$ to collect the plasma and harvest the clear supernatant, respectively, and then stored at $-70^{\circ} \mathrm{C}$ until analysis. Frozen plasma and urine samples were thawed at room temperature prior to each test.

Laboratory analyses. Immediately after blood sampling, whole blood without any anticoagulant was used for blood gas analysis with an i-STAT portable blood gas analyser (Abbott, Abbott Park, IL, USA), and the parameters including $\mathrm{pH}$, ionised $\mathrm{Ca}$ (iCa), bicarbonate $\left(\mathrm{HCO}_{3}{ }^{-}\right)$and partial pressure of carbon dioxide $\left(\mathrm{pCO}_{2}\right)$ were analysed. For measurement of minerals in thawed plasma and urine samples, a BS-400 auto-analyser (Mindray, Shenzhen, China) was used. All samples were tested on one day under the same conditions. The plasma parameters and urine mineral analyses included determination of $\mathrm{Ca}$, magnesium $(\mathrm{Mg})$ and creatinine (crea) levels. To estimate the amounts of macrominerals in urine, $\mathrm{Ca}$ and $\mathrm{Mg}$ levels were calculated along with their ratios to crea.

Statistical analyses. All results from the study were analysed using SigmaPlot 12.5 (Systat Software Inc., Chicago, IL, USA). One-way repeated-measures ANOVA followed by multiple comparisons with the Holm-Šidák method was used to identify significant differences within the group. Student's $t$-test was performed to compare the differences between the groups, and the Pearson method was used to confirm the correlations between the parameters.

\section{Results}

In the HYC group, the plasma Ca levels were significantly higher than their $0 \mathrm{~h}$ values until up to $8 \mathrm{~h}$ afterwards $(\mathrm{P}<0.05)$. They were also significantly higher than those seen in the CON group from 1 to $8 \mathrm{~h}$ ( $\mathrm{P}<0.05$, Fig. 1A). Furthermore, the HYC group had significantly different $\mathrm{Ca} /$ crea ratios from those of the CON group from $1 \mathrm{~h}$ to $12 \mathrm{~h}(\mathrm{P}<0.05)$, and they were higher from $1 \mathrm{~h}$ to $8 \mathrm{~h}$ after administration than at $0 \mathrm{~h}$ $(\mathrm{P}<0.05$, Fig. 1B). Mg levels were significantly higher in the HYC group from $1 \mathrm{~h}$ to $4 \mathrm{~h}$ after administration ( $\mathrm{P}<0.001$, Fig. 1C), this group's $\mathrm{Mg} /$ crea ratios were significantly different from $1 \mathrm{~h}$ to $4 \mathrm{~h}$ from those of the $\mathrm{CON}$ group, and they were significantly higher at $2 \mathrm{~h}$ and $4 \mathrm{~h}$ than at $0 \mathrm{~h}(\mathrm{P}<0.05$, Fig. 1D).

Blood $\mathrm{pH}$ in the HYC group showed a significant difference at $1 \mathrm{~h}$ and $2 \mathrm{~h}$ after administration from its $0 \mathrm{~h}$ value $(\mathrm{P}<0.05)$, and significant differences between the two experimental groups were confirmed at $1 \mathrm{~h}$ and $4 \mathrm{~h}$ after administration $(\mathrm{P}<0.05$, Fig. $1 \mathrm{E}) . \mathrm{HCO}_{3}{ }^{-}$also differed significantly between the groups at $1 \mathrm{~h}$ and $2 \mathrm{~h}$ after administration $(\mathrm{P}<0.05$, Fig. $1 \mathrm{~F})$, as did $\mathrm{pCO}_{2}$ at $2 \mathrm{~h}(\mathrm{P}<0.05$, Fig. $1 \mathrm{G})$.

In the correlation analysis, $\mathrm{pH}$ was significantly correlated with $\mathrm{HCO}_{3}{ }^{-}(r=0.781, \mathrm{P}<0.001)$; however, $\mathrm{pCO}_{2}$ was only weakly correlated with $\mathrm{pH}(r=0.085$, Table 1). In particular, the correlation between $\mathrm{pH}$ and $\mathrm{HCO}_{3}{ }^{-}$was higher in the $\mathrm{HYC}$ group $(r=0.820$, $\mathrm{P}<0.001$, Table 2). Levels of iCa in blood gas analysis were highly associated with the Ca concentration in the blood ( $r=0.917, \mathrm{P}<0.001$; Fig. $2 \mathrm{H}$; Table 1$)$, and the latter was highly correlated with $\mathrm{Ca} /$ crea and $\mathrm{pH}$ in all samples $(r=0.825$ and 0.466 , respectively; $\mathrm{P}<0.001$; Table 1), especially in the HYC group $(r=0.846$ and 0.688 , respectively; Table 2 ). 
(A)

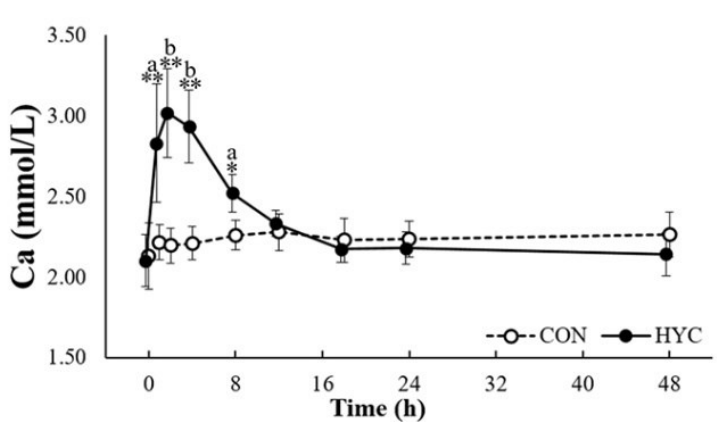

(C)

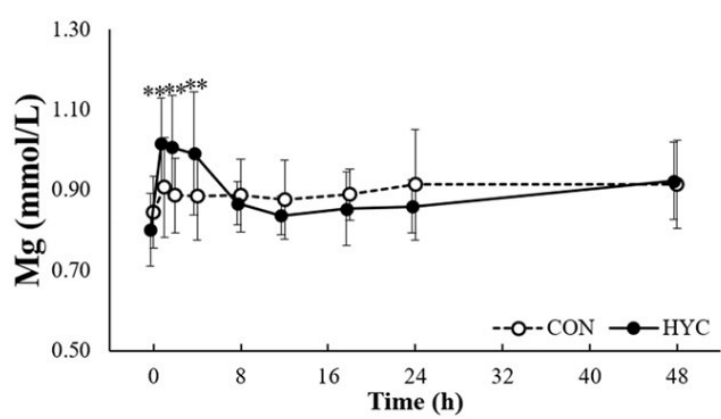

(E)

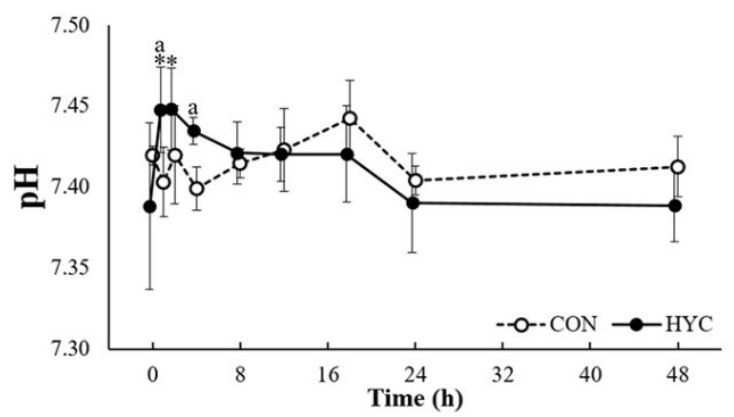

(G)

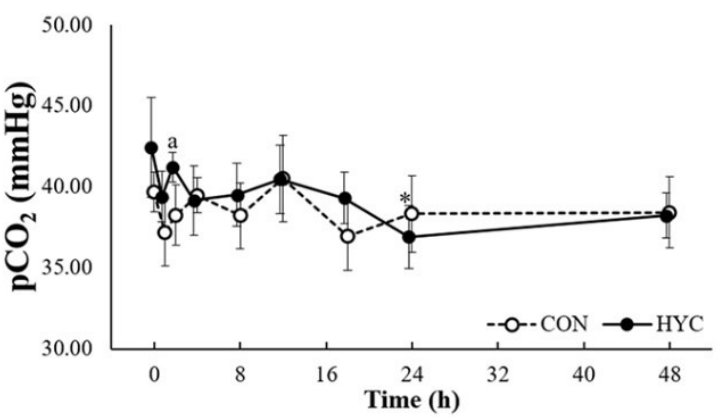

(B)

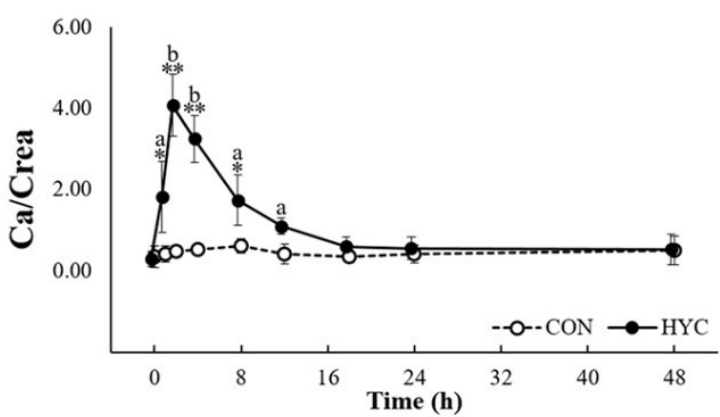

(D)

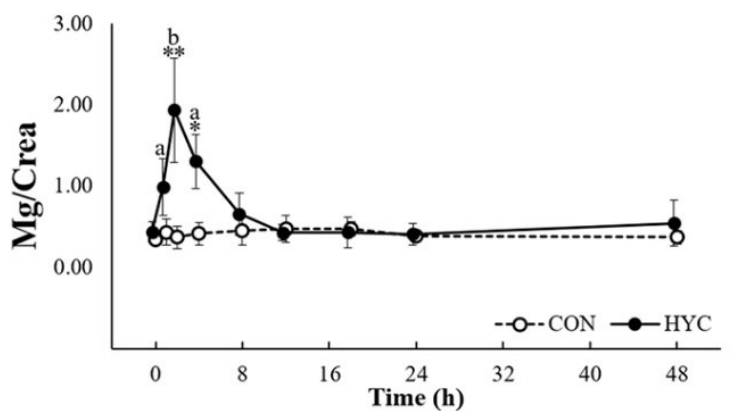

(F)

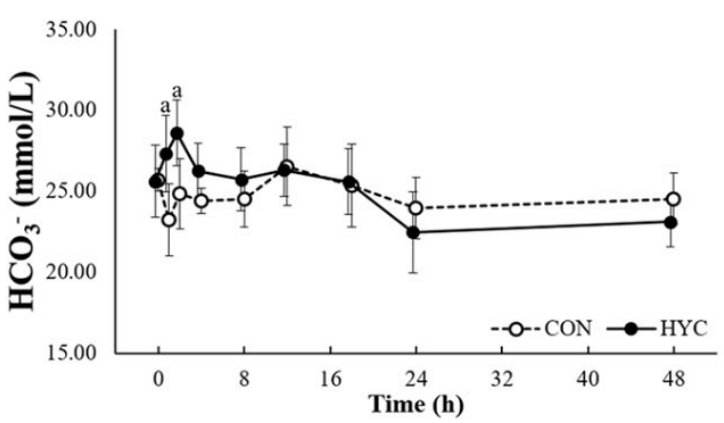

(H)

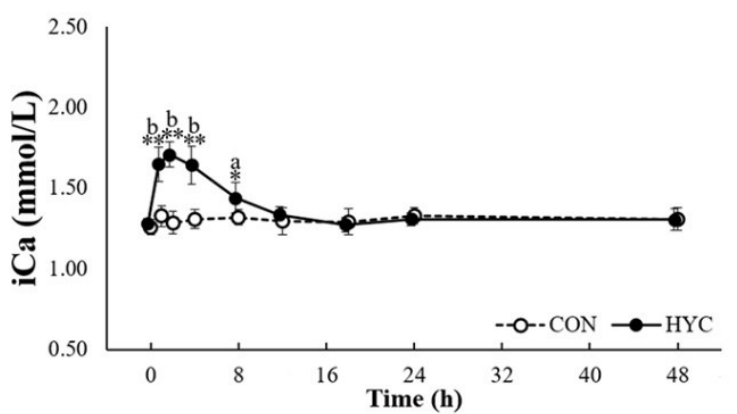

Fig 1. Changes in plasma mineral concentrations, urinary mineral excretions, and blood gas parameters in the control group (CON) and induced hypercalcaemic group (HYC)

$\mathrm{A}-\mathrm{Ca}$ concentration in plasma; $\mathrm{B}-\mathrm{Ca}$ excretion through urine $(\mathrm{Ca} /$ creatine (crea)); $\mathrm{C}-\mathrm{Mg}$ concentration in plasma; $\mathrm{D}-\mathrm{Mg}$ excretion through urine $\left(\mathrm{Mg}\right.$ /crea); $\mathrm{E}$ - blood $\mathrm{pH} ; \mathrm{F}$ - bicarbonate $\left(\mathrm{HCO}_{3}^{-}\right) ; \mathrm{G}$ - partial pressure of carbon dioxide $\left(\mathrm{pCO}_{2}\right) ; \mathrm{H}-$ ionised Ca. Data are expressed as means \pm standard deviation. ${ }^{*}$ - significant difference compared to $0 \mathrm{~h}(\mathrm{P}<0.05) ;{ }^{* *}-$ significant difference compared to 0 h $(\mathrm{P}<0.001)$; ${ }^{\mathrm{a}}$ - significant difference compared to $\mathrm{CON}(\mathrm{P}<0.05) ;{ }^{\mathrm{b}}$ - significant difference compared to $\mathrm{CON}(\mathrm{P}<0.001)$ 
Table 1. Results of Pearson correlation analysis of parameters in blood analyses in all individuals

\begin{tabular}{|c|c|c|c|c|c|c|c|c|c|}
\hline & & Test (n) & $\mathrm{Mg}$ & $\mathrm{Ca} /$ crea & $\mathrm{Mg} / \mathrm{crea}$ & $\mathrm{iCa}$ & $\mathrm{pH}$ & $\mathrm{HCO}_{3}^{-}$ & $\mathrm{pCO}_{2}$ \\
\hline \multirow{2}{*}{$\mathrm{Ca}$} & $r$ value & \multirow{2}{*}{90} & 0.599 & 0.825 & 0.698 & 0.917 & 0.466 & 0.490 & 0.220 \\
\hline & (P value) & & $(<0.001)^{* *}$ & $(<0.001)^{* *}$ & $(<0.001)^{* *}$ & $(<0.001)^{* *}$ & $(<0.001)^{* *}$ & $(<0.001)^{* *}$ & $(0.037)^{*}$ \\
\hline \multirow{2}{*}{$\mathrm{Mg}$} & $r$ value & \multirow{2}{*}{90} & & 0.381 & 0.438 & 0.410 & 0.340 & 0.262 & 0.004 \\
\hline & (P value) & & & $(<0.001)^{* *}$ & $(<0.001)^{* *}$ & $(<0.001)^{* *}$ & $(0.001)^{*}$ & $(0.013)^{*}$ & $(0.971)$ \\
\hline \multirow{2}{*}{$\mathrm{Ca} /$ crea } & $r$ value & \multirow{2}{*}{90} & & & 0.891 & 0.857 & 0.370 & 0.382 & 0.161 \\
\hline & (P value) & & & & $(<0.001)^{* *}$ & $(<0.001)^{* *}$ & $(<0.001)^{* *}$ & $(<0.001)^{* *}$ & $(0.131)$ \\
\hline \multirow{2}{*}{ Mg/crea } & $r$ value & \multirow{2}{*}{90} & & & & 0.712 & 0.345 & 0.380 & 0.181 \\
\hline & (P value) & & & & & $(<0.001)^{* *}$ & $(<0.001)^{* *}$ & $(<0.001)^{* *}$ & $(0.088)$ \\
\hline \multirow{2}{*}{$\mathrm{iCa}$} & $r$ value & \multirow{2}{*}{90} & & & & & 0.309 & 0.348 & 0.175 \\
\hline & (P value) & & & & & & $(0.003)^{*}$ & $(<0.001)^{* *}$ & $(0.098)$ \\
\hline \multirow{2}{*}{$\mathrm{pH}$} & $r$ value & \multirow{2}{*}{90} & & & & & & 0.781 & 0.085 \\
\hline & (P value) & & & & & & & $(<0.001)^{* *}$ & $(0.424)$ \\
\hline \multirow{2}{*}{$\mathrm{HCO}_{3}^{-}$} & $r$ value & \multirow{2}{*}{90} & & & & & & & 0.687 \\
\hline & (P value) & & & & & & & & $\overline{(<0.001)^{* *}}$ \\
\hline
\end{tabular}

$r$ - Pearson's correlation coefficient values; $*$ - significant difference between the hypercalcaemic group and the control group at $\mathrm{P}<0.05$; ** - significant difference between the hypercalcaemic group and the control group at $\mathrm{P}<0.001 ; \mathrm{Ca} / \mathrm{crea}-$ calcium/creatinine in urine; $\mathrm{Mg} / \mathrm{crea}$ - magnesium/creatinine in urine; $\mathrm{iCa}$ - ionised calcium; $\mathrm{HCO}_{3}^{-}$- bicarbonate; $\mathrm{pCO}_{2},-$ partial pressure of carbon dioxide

Table 2. Results of Pearson correlation analysis of $\mathrm{Ca}$ concentration with $\mathrm{pH}$ in the induced hypercalcaemic group

\begin{tabular}{|c|c|c|c|c|c|c|c|}
\hline & & Test (n) & $\mathrm{iCa}$ & $\mathrm{Ca} / \mathrm{crea}$ & $\mathrm{pH}$ & $\mathrm{HCO}_{3}^{-}$ & $\mathrm{pCO}_{2}$ \\
\hline \multirow{2}{*}{$\mathrm{Ca}$} & $r$ value & \multirow{2}{*}{45} & 0.933 & 0.846 & 0.688 & 0.672 & 0.206 \\
\hline & (P value) & & $(<0.001)^{* *}$ & $(<0.001)^{* *}$ & $(<0.001)^{* *}$ & $(<0.001)^{* *}$ & $(0.174)$ \\
\hline \multirow{2}{*}{$\mathrm{iCa}$} & $r$ value & \multirow{2}{*}{45} & & 0.860 & 0.542 & 0.549 & 0.194 \\
\hline & (P value) & & & $(<0.001)^{* *}$ & $(<0.001)^{* *}$ & $(<0.001)^{* *}$ & $(0.201)$ \\
\hline \multirow{2}{*}{$\mathrm{Ca} /$ crea } & $r$ value & \multirow{2}{*}{45} & & & 0.511 & 0.486 & 0.125 \\
\hline & (P value) & & & & $(<0.001)^{* *}$ & $(<0.001)^{* *}$ & $(0.412)$ \\
\hline \multirow{2}{*}{$\mathrm{pH}$} & $r$ value & \multirow{2}{*}{45} & & & & 0.820 & 0.041 \\
\hline & (P value) & & & & & $(<0.001)^{* *}$ & $(0.788)$ \\
\hline \multirow{2}{*}{$\mathrm{HCO}_{3}{ }^{-}$} & $r$ value & \multirow{2}{*}{45} & & & & & 0.603 \\
\hline & (P value) & & & & & & $(<0.001)^{* *}$ \\
\hline
\end{tabular}

$r$ - Pearson's correlation coefficient values; $*$ - significant difference between the hypercalcaemic group and the control group at $\mathrm{P}<0.05$; ** - significant difference between the hypercalcaemic group and the control group at $\mathrm{P}<0.001 ; \mathrm{Ca} / \mathrm{crea}-$ calcium/creatinine in urine; $\mathrm{iCa}$ - ionised calcium; $\mathrm{HCO}_{3}{ }^{-}$- bicarbonate; $\mathrm{pCO}_{2}$ - partial pressure of carbon dioxide

\section{Discussion}

Administration of $\mathrm{Ca}$ borogluconate caused a significant increase in plasma Ca concentration and urinary $\mathrm{Ca}$ excretion. Simultaneously, blood $\mathrm{pH}$ was more basic in the HYC group. The changing pattern of blood $\mathrm{pH}$ was similar to that of $\mathrm{HCO}_{3}{ }^{-}$, and the two values showed a strong correlation. Even though an acidic solution was administered, mildly alkaline blood $\mathrm{pH}$ was confirmed in the HYC group. This alteration was the opposite of the results of our previous study inducing the opposite state, hypocalcaemia, in which the deficit of $\mathrm{Ca}$ caused more acidic plasma $\mathrm{pH}$, and probably resulted in the maximisation of the effect of PTH $(9,10,12)$. As estimated in previous studies, there is a mechanism by which a decrease in blood $\mathrm{pH}$ results in an increase in the activity of PTH $(9,10,13)$. The relationship between calcitonin, which lowers $\mathrm{Ca}$ levels in blood in a hypercalcaemic state, and blood $\mathrm{pH}$ has only been verified experimentally in hypocalcaemic status or in vitro $(6,11)$. Our in vivo results suggest that a spontaneous increase in blood $\mathrm{pH}$ after inducing hypercalcaemia strengthens the action of calcitonin. We additionally posit that the spontaneous increase in blood $\mathrm{pH}$ in the $\mathrm{HYC}$ group was due to the $\mathrm{HCO}_{3}{ }^{-}$buffer system, citing the verified correlation between $\mathrm{pH}$ and $\mathrm{HCO}_{3}{ }^{-}$in support. Thus, blood $\mathrm{Ca}$ concentration higher than the normal range activates a series of homeostatic processes and activates the $\mathrm{HCO}_{3}{ }^{-}$buffer system to change blood $\mathrm{pH}$, creating an optimal environment for the processes to operate efficiently. By maximising the effect of calcitonin, $\mathrm{Ca}$ reabsorption in the kidneys is suppressed and excretion of $\mathrm{Ca}$ through urine is increased, thereby returning $\mathrm{Ca}$ levels in the blood to their normal state. In the $\mathrm{HYC}$ group, $\mathrm{Ca} /$ crea and $\mathrm{Mg} / \mathrm{crea}$ increased significantly. Levels of $\mathrm{Ca}$ were higher in the HYC group for $8 \mathrm{~h}$ after administration of the drug compared to the pre-dosing levels. This was presumed to be due to the action of calcitonin, as its secretion is dependent on blood Ca levels and it controls the excretion of macrominerals via urine $(3,5)$. In addition to the effect of calcitonin, as blood $\mathrm{pH}$ increases, the binding of $\mathrm{iCa}$ to albumin increases, leading to a decrease in $\mathrm{iCa}$ levels in the blood to 
an extent which varies depending on the concentration of albumin in the blood $(9,10)$.

In conclusion, this study confirmed the change in blood $\mathrm{pH}$ concomitantly with the change of $\mathrm{Ca}$ concentration in blood during the induction of hypercalcaemia and recovery to normocalcaemia. Furthermore, our results suggest that this $\mathrm{pH}$ change was caused by the alteration of $\mathrm{HCO}_{3}{ }^{-}$concentration. Although mineralotropic hormones were not measured in the course of the experiment, changes in blood $\mathrm{pH}$ and $\mathrm{HCO}_{3}{ }^{-}$are presumed to be mechanisms that maintain $\mathrm{Ca}$ homeostasis. Therefore, in further studies, measurement of mineralotropic hormones at varied breeding stages and larger numbers of experimental animals are needed to clarify the mechanism.

Conflict of Interests Statement: The authors declare that there is no conflict of interests regarding the publication of this article.

Animal Rights Statement: This study was approved by the Institutional Animal Care and Use Committee of Seoul National University (SNU-190522-3).

Financial Disclosure Statement: This study was partially supported by the Research Institute for Veterinary Science at the Seoul National University.

\section{References}

1. Alexander R.T., Cordat E., Chambrey R., Dimke H., Eladari D.: Acidosis and urinary calcium excretion: insight from genetic disorders. J Am Soc Nephrol 2016, 27, 3511-3520, doi: 10.1681/ASN.2016030305.

2. Cai C., Kong Y., Wo D., Wang J.: Changes of macrominerals and calcitropic hormones in serum of periparturient dairy cows subject to subclinical hypocalcaemia. J Dairy Res 2018, 85, 12-16, doi: $10.1017 / \mathrm{S} 0022029918000031$.
3. Davey R.A., Findlay D.M.: Calcitonin: physiology or fantasy? J Bone Miner Res 2018, 28, 973-979, doi: 10.1002/jbmr.1869.

4. Davidson J.A., Beede D.K.: Exercise training of late-pregnant and nonpregnant dairy cows affects physical fitness and acid-base homeostasis. J Dairy Sci 2009, 92, 548-562, doi: 10.3168/jds.2008-1458.

5. Felsenfeld A.J., Levine B.S.: Calcitonin, the forgotten hormone: does it deserve to be forgotten? Clin Kidney J 2015, 8, 180-187, doi: $10.1093 / \mathrm{ckj} / \mathrm{sfv} 011$.

6. Goldring S.R.: Molecular biology and regulation of the calcitonin receptor. J Bone Miner Metab 1997, 15, 51-58, doi: 10.1007/BF0249074.

7. Hernández-Castellano L.E., Hernandez L.L., Bruckmaier R.M.: Review: endocrine pathways to regulate calcium homeostasis around parturition and the prevention of hypocalcemia in periparturient dairy cows. Animal 2020, 14, 330-338, doi: 10.1017/S1751731119001605.

8. Horst R.L., Goff J.P., Reinhardt T.A.: Adapting to the transition between gestation and lactation: differences between rat, human and dairy cow. J Mammary Gland Biol Neoplasia 2005, 10, 141-153, doi: 10.1007/s10911-005-5397-x.

9. López I., Aguilera-Tejero E., Estepa J.C., Rodríguez M., Felsenfeld A.J.: Role of acidosis-induced increases in calcium on PTH secretion in acute metabolic and respiratory acidosis in the dog. Am J Physiol Endocrinol Metab 2004, 286, E780-E785, doi: 10.1152/ajpendo.00473.2003.

10. López I., Rodríguez M., Felsenfeld A.J., Estepa J.C., Aguilera-Tejero E.: Direct suppressive effect of acute metabolic and respiratory alkalosis on parathyroid hormone secretion in the dog. J Bone Miner Res 2003, 18, 1478-1485, doi: 10.1359/jbmr.2003.18.8.1478.

11. Rodríguez E.M., Bach A., Devant M., Aris A.: Is calcitonin an active hormone in the onset and prevention of hypocalcemia in dairy cattle? J Dairy Sci 2015, 99, 3023-3030, doi: 10.3168/ jds.2015-10229.

12. Ro Y., Choi W., Park J., Choe E., Kim D.: Changes in plasma pH and blood and urinary macromineral concentrations in experimentally induced hypocalcemic cows with $\mathrm{Na}_{2}$ EDTA. J Vet Med Sci 2020, 82, 962-966, doi: 10.1292/jvms.20-0048.

13. Uhl E.W.: The pathology of vitamin D deficiency in domesticated animals: An evolutionary and comparative overview. Int J Paleopathol 2018, 23, 100-109, doi: 10.1016/j.ijpp.2018.03.001.

14. Wilkens M.R., Muscher-Banse A.S.: Review: Regulation of gastrointestinal and renal transport of calcium and phosphorus in ruminants. Animal 2020, 14, s29-s43, doi: 10.1017/ S1751731119003197. 